\title{
Rock Physics Modelling for Estimating of Reservoir Tight Sand Quality in Bintuni Basin, West Papua, Indonesia
}

\author{
Pemodelan Fisika Batuan untuk Estimasi Kualitas Reservoir Tight Sand, Cekungan Bintuni Papua
}

\author{
Barat, Indonesia
}

\author{
Ambarsari D. S.* dan Winardhi S. \\ Teknik Geofisika, Fakultas Teknik Pertambangan dan Perminyakan, Institut Teknologi Bandung, \\ Jalan Ganesa No 10, Bandung, 40132 \\ *Email: donasita.22@gmail.com
}

\begin{abstract}
Permeability is a key to determine the quality of reservoir. Reservoir quality can be defined as the ratio between permeability and porosity of a rock. Besides, permeability is not influenced by porosity solely, there are other factors which affect the value of the permeability of a rock. One of them is affected by the pore structure, which includes turtuosity, surface area, and grain size. To determine how much these factors affect the permeability of a rock, it takes an elastic parameters that can be an indicator of the quality reservoir e.g pore space stiffness and critical porosity.Primary data such as petrophysics, XRD data, and permeability are used as input data to determine the quality of reservoir. By using Zimmerman's equation and Nur's model, we will get the value of pore space stiffness and critical porosity at each point. The combination of rock quality equation derived from Kozeny Carman's with elastic parameters as indicators produces qualitative rock quality identification. Results of this study is able to show that the pore space stiffness and critical porosity can represent turtuosity, surface area, and grain size of a rock which lead to the determination of rock quality. The method proposed in the present study demonstrated an excellence reservoir quality prediction based on the relation between petrophysical parameters with elastic parameters.
\end{abstract}

Keywords: permeability, rock quality, pore space stiffness, critical porosity

Abstrak: Permeabilitas menjadi parameter yang sangat penting dalam penentuan kualitas reservoir. Kualitas reservoir dapat didefinisikan sebagai perbandingan antara permeabilitas dengan porositas. Salah satu faktor utama yang mempengaruhi permeabilitas adalah porositas, namun masih terdapat faktor-faktor lainnya yang mempengaruhi besarnya nilai permeabilitas. Salah satunya dipengaruhi oleh stuktur pori batuan, yang merupakan fungsi dari turtuosity, surface area, dan besar butir. Untuk mengetahui seberapa besar faktor tersebut mempengaruhi permeabilitas suatu batuan, maka dibutuhkan suatu parameter elastik yang dapat menjadi indikator penentu kualitas reservoir. Dalam penelitian ini, parameter elastik yang digunakan adalah pore space stiffness dan critical porosity. Data-data primer seperti data log, data XRD, serta parameter reservoir khususnya permeabilitas digunakan sebagai data input untuk pemodelan kualitas reservoir. Parameter elastic pore space stiffness dan critical porosity diperoleh dari perhitungan menggunakan persamaan Zimmerman dan model Nur. Hasil penelitian ini berhasil menunjukkan bahwa pore space stiffness dan critical porosity mampu merepresentasikan nilai turtuosity dan besar butir suatu reservoir.

Kata kunci: permeabilitas, kualitas reservoir, pore space stiffness, critical porosity

\section{PENDAHULUAN}

Mayoritas sumber energi di Indonesia masih bergantung pada bahan bakar fosil, tetapi kenyataannya bahan bakar fosil merupakan sumber daya yang tidak bisa diperbarui dan produksinya terus menurun. Dengan didasari masalah tersebut, upaya yang bisa dilakukan yaitu melakukan kegiatan eksplorasi di cekungan kawasan timur Indonesia dengan target reservoir yang belum banyak dikembangkan saat ini, yaitu reservoir batupasir tight.

Batupasir tight merupakan salah satu jenis reservoir yang jarang ditargetkan sebagai reservoir utama. Hal ini dikarenakan batupasir tight memiliki nilai porositas rendah akibat sudah mengalami proses kompaksi. Dalam Pride (2005) faktor konsolidasi $(\alpha)$ digunakan sebagai salah satu parameter yang menggambarkan derajat kompaksi suatu batuan. Semakin kecil nilai $\alpha$ maka batuan semakin terkompaksi. Faktor ini tentu akan mempengaruhi kualitas dari suatu batuan. Properti fisis batuan lainnya yang mempengaruhi kualitas batuan adalah permeabilitas dan porositas.

Semakin tinggi permeabilitas dan porositas maka kualitas reservoir akan semakin bagus. Namun, suatu batuan dengan porositas tinggi belum tentu permeabilitasnya tinggi, tergantung bentuk dan ukuran butir. Oleh karena itu, penelitian kali ini dilakukan untuk melihat bagaimana hubungan antara antara permeabilitas dan porositas dengan parameter elastis yang diturunkan dari metode fisika bat- 
Tabel 1. Nilai alpha dominan pada setiap sumur.

\begin{tabular}{lcr}
\hline Sumur & Kedalaman $(\mathrm{m})$ & Alpha \\
\hline DN 2 & $3709-3976$ & 2 \\
DN 3 & $4175-4310$ & 1.5 \\
DN 4 & $4219-4450$ & 1.15 \\
\hline
\end{tabular}

uan seperti misalnya pore space stiffness dan critical porosity dari reservoir batupasir tight.

\section{DATA DAN METODOLOGI}

\subsection{Data}

Data yang digunakan dalam studi ini merupakan data pengukuran well-log yang meliputi pengukuran kecepatan gelombang $\mathrm{P}$, densitas, saturasi, dan porositas dari tiga sumur yaitu sumur "DN2", "DN3" dan "DN4". Sedangkan untuk data permeabilitas hanya tersedia pada sumur "DN 3" dan "DN 4". Jenis batuan pada zona penelitian kali ini merupakan batupasir tight, dengan kedalaman zona target mencapai kedalaman $4000 \mathrm{~m}$.

\subsection{Metodologi}

Penelitian ini merupakan pemodelan fisika batuan berdasarkan properti elastik batuan pada masing-masing kedalaman zona target pada sumur "DN 2", "DN 3", dan "DN 4". Terdapat beberapa tahapan yang dilakukan dalam melakukan pemodelan fisika batuan pada zona target. Secara lebih detail tahapan-tahapan tersebut di gambarkan didalam diagram alir berikut.

Pemodelan modulus bulk mineral menggunakan pendekatan yang dilakukan oleh Pride (2005). Dalam teknik pendekatan ini, parameter pendukung yang digunakan adalah faktor konsolidasi $(\alpha)$. Berikut merupakan nilai dimonan $\alpha$ untuk masing masing sumur.

Metode pore space stiffness yang digunakan dalam pemodelan kali ini didasari oleh persamaan Zimmerman (Mavko, 2009). Dari hasil pemodelan tersebut, gradien dari hasil crossplot antara "Kdry/Kmin" terhadap porositas merupakan nilai konstanta $\mathrm{k}$ yang menggambarkan bentuk pori batuan. Semakin besar nilai k maka batuan akan cenderung lebih stiff dibanding dengan batuan bernilai k kecil.

Gambar 1 menunjukan persebaran konstanta k di setiap sumur. Pada sumur "DN 2" mayoritas nilai k berada pada nilai $\mathrm{k}=0.3$, untuk sumur "DN 3" nilai $\mathrm{k}$ berada diantara $\mathrm{k}$ $=0.3-0.5$, dan sumur "DN 4" diantara $\mathrm{k}=0.35-0.5$. Dari persebaran nilai $\mathrm{k}$, dapat diketahui bahwa bentuk pori pada ketiga sumur tidak jauh berbeda, hanya saja pada sumur "DN 2" bentuk pori lebih seragam dibanding kedua sumur lainnya.

Pemodelan fisika batuan kedua menggunakan Model Nur (Mavko, 2009) bertujuan untuk mengetahui nilai critical porosity pada batuan target disetiap sumur. Hasil dari pemodelan ini adalah nilai critical porosity yang diilustrasikan sebagai garis diagonal berwarna hitam dalam crossplot "Kdry/Kmin" terhadap porositas (Gambar 2). Critical porosity $\left(\phi_{c}\right)$ digunakan sebagai parameter elastik yang sebanding dengan grain size (d). Ketika nilai $\phi_{c}$ besar, maka

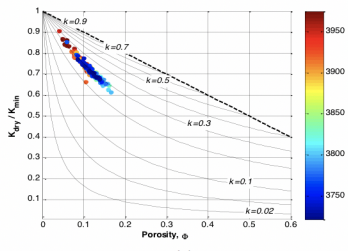

(a)

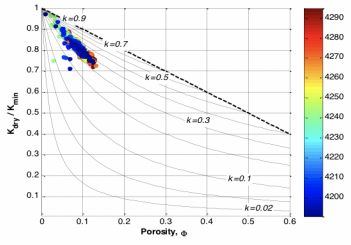

(b)
Gambar 1. Plotting kurva pore space stiffness color key kedalaman (a) Sumur "DN 2" (b) Sumur "DN 3" (c) Sumur "DN 4"

grain size dari batuan tersebut akan relatif berukuran besar. Nilai critical porosity pada ketiga sumur berkisar dari $0.4 \mathrm{~s} / \mathrm{d} 0.6$.

\section{HASIL DAN DISKUSI}

Tahap awal yang dilakukan untuk mengetahui kualitas reservoir adalah membandingkan nilai permeabilitas dengan porositas batuan (Gambar 3). Plotting antara permeabilitas dengan porositas menunjukan bahwa data-data masih tersebar secara acak (scattered). Namun, secara garis besar hubungan antara permeabilitas dan porositas adalah berbanding lurus.

Rock quality dapat didefinisikan sebagai perbandingan permeabilitas dengan porositas. Dalam mengidentifikasi kualitas batuan, akan berkaitan dengan kemampuan batuan untuk meloloskan fluida. Kozeny-Carman merumuskan suatu persamaan untuk mengestimasi permeabilitas dari suatu batuan porous sebagai fungsi dari porositas $(\phi)$, surface area $(S)$, turtuosity $(\tau)$, dan shape factor $\left(k_{0}\right)$.

$$
k=\frac{\phi^{3}}{k_{0} \tau S^{2}}
$$

Persamaan (1) dapat di sederhanakan menjadi:

$$
\begin{gathered}
k=C \phi^{3} \\
C=\frac{k}{\phi^{3}}=\frac{1}{k_{o} \tau S^{2}}
\end{gathered}
$$

Dengan $\mathrm{C}$ adalah fungsi dari surface area $(\mathrm{S})$, turtuosity $(\tau)$, dan shape factor $\left(k_{0}\right)$. Parameter ini mewakili struktur pori suatu batuan, ketika $\mathrm{C}$ besar maka turtuosity dan surface area akan kecil. Dapat disimpulkan bahwa semakin rumit struktur suatu batuan maka nilai $\mathrm{C}$ akan rendah, begitu juga sebaliknya.

$$
\left(\frac{k}{\phi}\right)^{0.5}=\phi(C)^{0.5}
$$




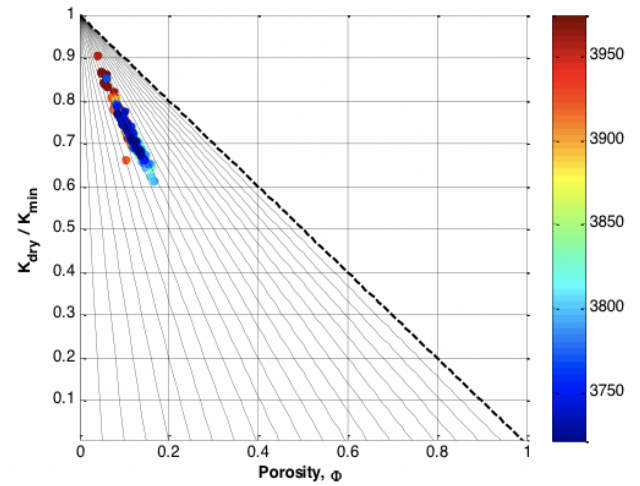

(a)

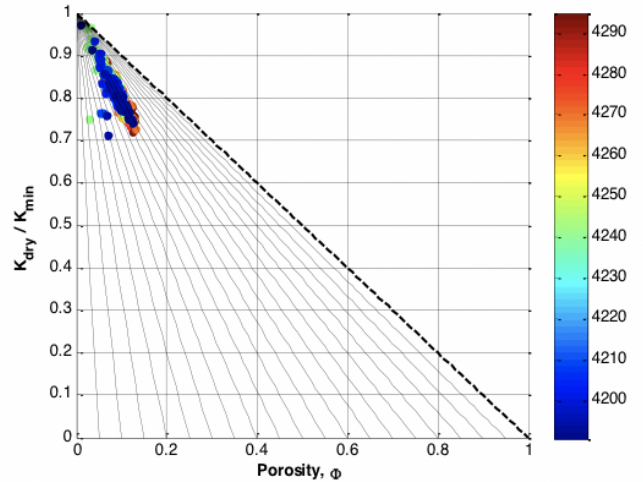

(b)

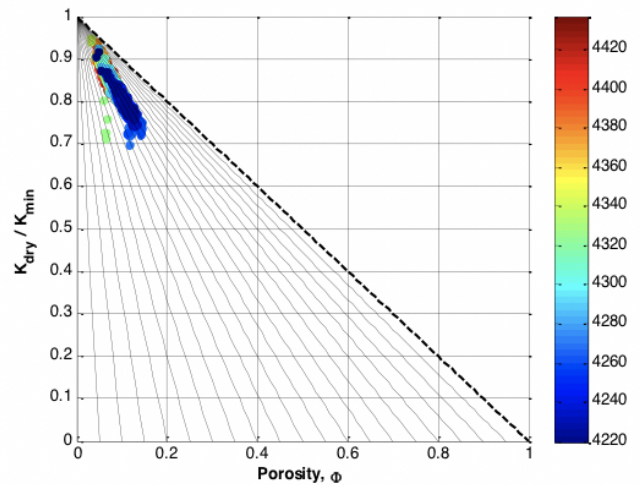

(c)

Gambar 2. Plotting kurva Nur (a) Sumur "DN 2" (b) Sumur "DN 3" (c) Sumur "DN 4"

Apabila Persamaan (2) disusun kembali menjadi persamaan (3) kemudian dilakukan plotting antara $\left(\frac{k}{\phi}\right)^{0.5}$ terhadap C dalam skala logaritma, (Permadi, 2011) akan menunjukan hubungan antara rock quality terhadap suatu parameter yang merupakan fungsi dari surface area, dan turtuosity batuan. Dengan mengasumsikan bahwa surface area (S) berbanding terbalik dengan grain size (d), maka Persamaan (2) dapat disusun menjadi:

$$
C \approx \frac{d}{\tau}
$$

Parameter elastik yang berbanding lurus dengan grain size (d), adalah critical porosity $\left(\phi_{c}\right)$. Hal ini dikarenakan saat $\phi_{c}$ suatu batuan besar, maka grain size akan besar pula. Contoh suatu batuan dengan $\phi_{c}=0.4$, ketika porositasnya mendekati 0.4 batuan tersebut masih bisa berperan sebagai reservoir. Hal ini terjadi ketika grain size cukup besar sehingga bisa mempertahankan bentuk sebagai suatu batuan. Sedangkan turtuosity akan berkaitan dengan modulus bulk pori $\left(K_{\phi}\right)$, dimana $K_{\phi}$ akan sama dengan modulus bulk matriks $\left(K_{\text {min }}\right)$ dikurangi dengan modulus bulk dryrock $\left(K_{d r y}\right)$. Suatu batuan dengan nilai $K_{\phi}$ besar, akan memiliki $K_{d r y}$ yang besar pula. Untuk menyatakannya kedalam persamaan matematis :

$$
\begin{gathered}
\frac{d}{\tau} \approx \frac{\phi_{c}}{\frac{1}{\left(\frac{K_{\min }-K_{d r y}}{K_{\min }}\right)}} \\
C \approx \frac{d}{\tau} \approx \phi_{c}\left(1-\frac{K_{d r y}}{K_{\min }}\right)
\end{gathered}
$$

Ketika $K_{d r y}$ bernilai sangat kecil, maka $\tau$ akan mendekati 1 , dan ketika $K_{d r y}$ mendekati atau sama dengan $K_{\text {min }}$ maka $\tau$ akan mendekati inf. Dapat disimpulkan bahwa pada saat $K_{d r y}$ mendekati atau sama dengan $K_{\min }$ batuan tersebut sangat terkompaksi sehingga tidak ada jalur atau pori sebagai jalan keluar fluida, yang menyebabkan permeabilitasnya akan sangat kecil.

Dengan mengombinasikan plotting antara $(k / \phi)^{0.5}$ terhadap C dalam skala logaritma, (Permadi, 2011) dan menambahkan nilai dari Persamaan (5) sebagai indikator yang merupakan fungsi dari surface area, dan turtuosity batuan (Gambar 4) dapat terlihat pemisahan gradien untuk setiap batuan dengan kualitas yang berbeda-beda.

Ketika menggunakan Persamaan (5) sebagai indikator pemisah, dapat terlihat dominasi nilai tinggi berada di bagian paling atas dengan gradasi kearah bawah semakin rendah. Maka dapat disimpulkan bahwa $\phi_{c}\left(1-K_{d r y} / K_{\text {min }}\right)$ dapat digunakan sebagai indikator untuk klasifikasi kualitas 


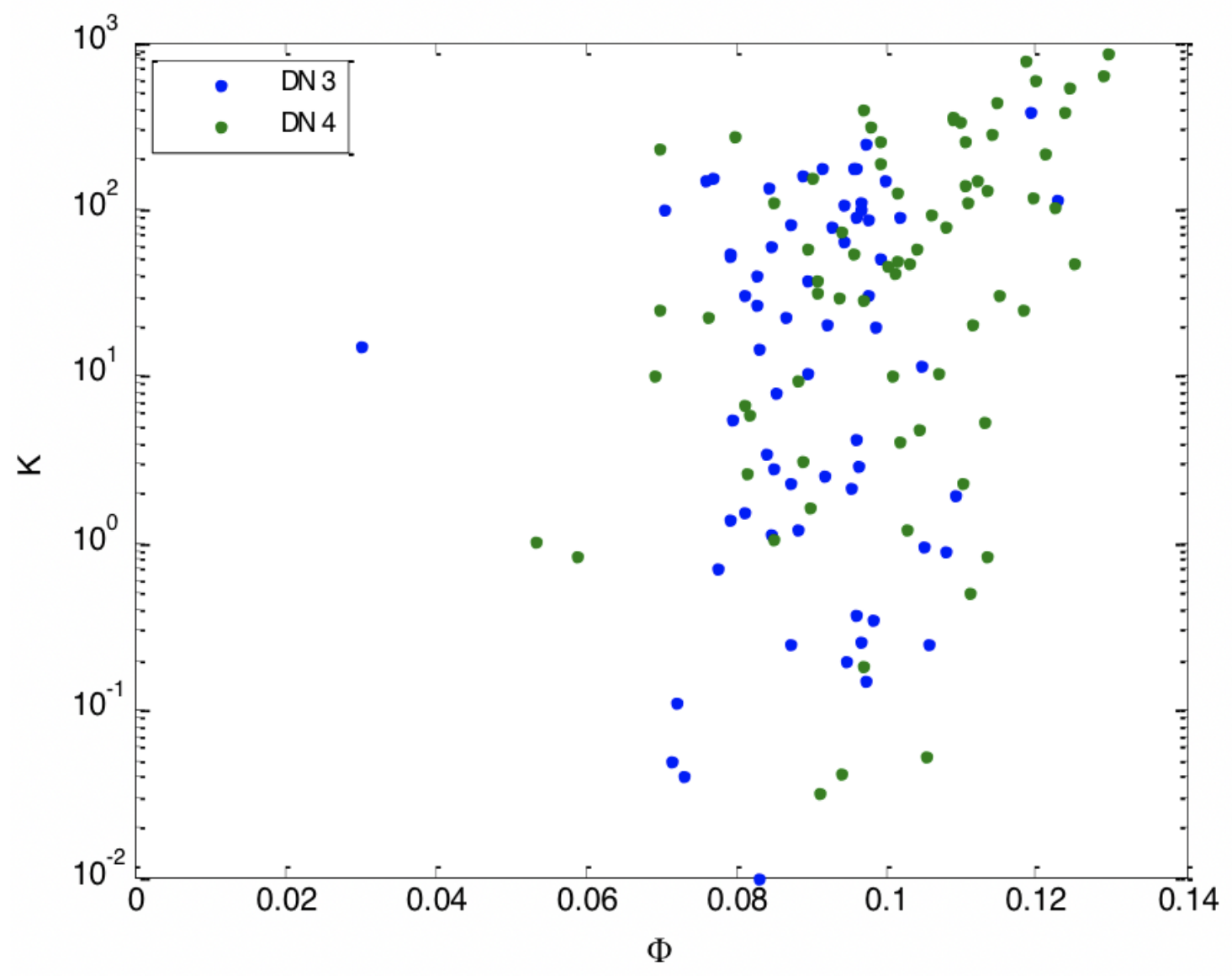

Gambar 3. Plotting porositas-permeabilitas sumur "DN 3" dan "DN 4"

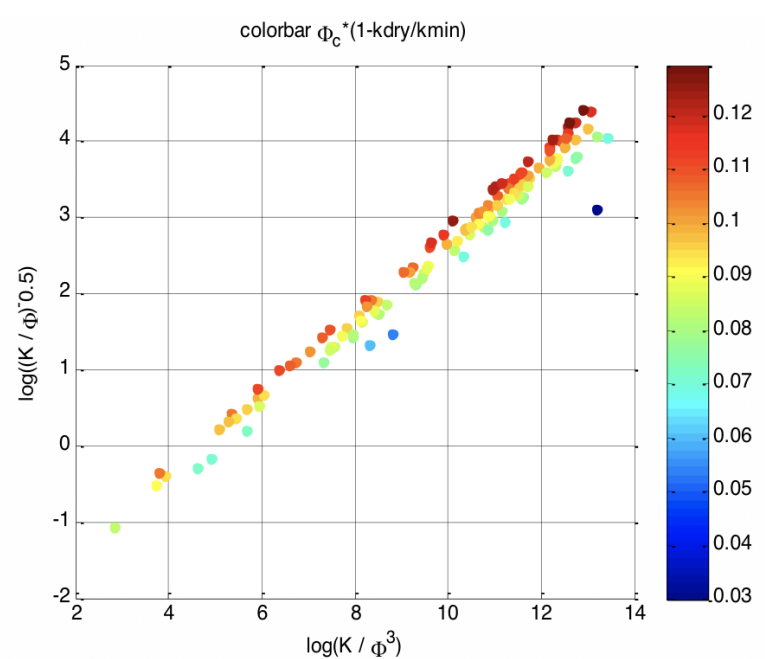

Gambar 4. Plotting antara $(k / \phi)^{0.5}$ dan C, color key $\phi_{c}(1-$ $\left.K_{d r y} / K_{\min }\right)$

reservoir berdasarkan struktur pori batuan, sebagai fungsi dari turtuosity dan surface area.

\section{KESIMPULAN}

Kualitas reservoir akan berkaitan dengan permeabilitas suatu batuan, dimana permeabilitas akan dipengaruhi oleh beberapa faktor diantaranya grain size dan turtuosity. Parameter elastik yang dapat dikaitkan dengan kedua faktor tersebut adalah critical porosity dan pore space stiffness. Grain size akan sebanding dengan critical porosiy sedangkan turtuosity akan berhubungan dengan pore space stiffness. Ketika menggunakan $\phi_{c}\left(1-K_{d r y} / K_{\min }\right)$ sebagai indikator pemisah kualitas reservoir, dengan kualitas terbaik akan memiliki gradient yang paling tinggi, sedangkan kualitas rendah dicerminkan dengan gradient rendah. Indikator tersebut dapat digunakan sebagai indikator untuk klasifikasi kualitas reservoir berdasarkan pemisahan struktur pori batuan, sebagai fungsi dari turtuosity dan surface area.

\section{DAFTAR PUSTAKA}

Amaefule, Jude O dan Altunbay, Mehmet. (1993). Enhanced Reservoir Description: Using Core and Log Data to Identify Hydraulic (Flow) Units and Predict Permeability in Uncoreed Intervals/Wells. SPE 26436, page 205-220.

Chapuis, Robert P., dan Aubertin, Michel. (2003). Predicting the Cofficient of Permeability of Soils using the Kozeny-Carman Equation. Montreal: Department CGM, Ecole Polytechnique de Montreal. 
Chandra, Tanmay. (2008). Permeability Estimation using Flow Zone Indicator from Well-log Data. Dhanbad: Dept. Of Applied Geophysics, ISM University.

Kumar, D. (2006). A Tutorial on Gassmann Fluid Substitution: Formulation, Algorithm and Matlab Code. Geohorizons, January 2006, page 5-12

Lee, Myung W. (2005). Proposed Moduli of Dry Rock and Their Application to Predicting Elatic Velocities of Sandstones. Virginia: U.S Geological Survey Scientific Investigastion Report 2005-5119, $14 \mathrm{p}$

Mavko, G., Mukerji, T., dan Dvorkin, J. (2009). The Rock Physics Handbook. New York: Cambridge University Press.

Nur, A., Mavko, G., Dvorkin, J., dan Gal, D., (1995). Critical Porosity: The Key to relating Physical Properties to Porosity in Rocks. In Proc. 65th Ann. Int. Meeting, Soc. Expl. Geophys., vol 878. Tulsa, OK: Society of Exploration Geophysicists.

Panuju, F, Mufdi., P, Imam., R, Ginanjar., F, Iskandar., dan Buskamal. (2012). Zona Biostratigrafi Nanoplankton Berumur Coniacian-Maastrichtian (Kapur Akhir) Cekungan Bintuni, Kepala Burung, Papua. Jakarta: Exploration Division, PPPTMBG, LEMIGAS.

Permadi, Pudji., and Kurnia, Ivan. (2011). Rock Type Based Permeability Prediction Using Routine and Special Core Analysis Data. Bandung: Institut Teknologi Bandung.

Pride, S. R. (2005). Relationships Between Seismic and Hydrological Properties, In Rubin, Y., and Hubbard, S. eds. Hydrogeophysics: New York, Kluwer Academy, p. 217-255 Russel, B. (2013). A Gassman Constituent Rock Physics Template. CSEG Recorder. 